\title{
AETIOLOGICAL FACTORS AND CLINICOPATHOLOGICAL PROFILE OF GALLBLADDER MALIGNANCY
}

\author{
Abhishek Jina ${ }^{1}$, Santosh Upreti $^{2}$
}

1Assistant Professor, Department of General Surgery, B. R. D. Medical College, Gorakhpur, Uttar Pradesh, India.

2Resident, Department of General Surgery, Himalayan Institute of Medical Sciences, Deharadun, Uttarakhand, India.

\section{BACKGROUND}

\section{ABSTRACT}

Early stages of gall bladder cancer are difficult to detect due to the absence of appropriate symptoms and signs. Previous studies have reported the correlation of clinical parameters, dietary habits and socioeconomic status of subjects to incidences of gall bladder cancer.

Elucidation of various regional aetiological parameters as well as clinical presentation and histopathology of gall bladder malignancy will help in precise diagnosis of this disease in concerned patients.

\section{MATERIALS AND METHODS}

This retrospective descriptive study was carried out with both prospective $(n=87)$ and retrospective $(n=110)$ data analysis over a period of one and three years respectively.

\section{RESULTS}

Manifestation of this disease was mostly observed in middle-aged groups of subjects. Multiparous female individuals were found to be more predisposed to this disease than others. Incidences of gall bladder carcinoma were also found to be affected by dietary habits and socioeconomic status with most of the patients hailing from rural habitats. Gall stones were present in $80 \%$ of cases diagnosed with gall bladder cancer. Most of these patients were diagnosed with metastasising or infiltrating adenocarcinoma. Only single incidences of papillary and adenosquamous carcinoma of the gall bladder was found in two patients.

\section{CONCLUSION}

Results obtained in this study indicate that aetiological factors causing gall bladder carcinoma are continuously changing for a population subgroup with corresponding alterations in lifestyle, exposure to toxins and dietary habits. In this study, conclusive diagnosis of gall bladder cancer was provided by laparoscopic examinations. However, further investigations are required to determine the preventable factors causing the widespread manifestations of this disease.

\section{KEY WORDS}

Gall Bladder Carcinoma, Aetiological Factors, Diagnostic Tools, Laparotomy.

HOW TO CITE THIS ARTICLE: Jina A, Upreti S. Aetiological factors and clinicopathological profile of gallbladder malignancy. J. Evolution Med. Dent. Sci. 2018;7(36):4038-4044, DOI: 10.14260/jemds/2018/902

\section{BACKGROUND}

Cancer of the gall bladder is an uncommon malignancy of the biliary tract that reportedly occurs more in the developing countries than the developed ones. ${ }^{1}$ Absence of symptoms at the initial stage of this disease causes difficulty in designing treatment strategies for the same. ${ }^{1}$ The dismal prognosis of this disease is caused by the absence of the serosal layer between the gall bladder and the liver facilitating hepatic invasion and metastasis of this disease. ${ }^{2}$

Geography, ethnicity and culture are found to affect the occurrence of this disease indicating the crucial role of significant genetic and environmental parameters in guiding the development and advancement of the disease. ${ }^{3}$ Manifestation of gall bladder carcinoma have been found to be correlated to chronic infection of the gall bladder, exposure to toxic chemicals and heavy metals as well as dietary habits. ${ }^{1}$

'Financial or Other Competing Interest': None.

Submission 19-07-2018, Peer Review 17-08-2018,

Acceptance 23-08-2018, Published 03-09-2018.

Corresponding Author:

Dr. Abhishek Jina

\#27, Doctors Enclave, Rapti Nagar,

Phase 3, Near Shahpur Thana,

Gorakhpur-273004, Uttarakhand, India.

E-mail: drabhishekjina@gmail.com

DOI: $10.14260 /$ jemds $/ 2018 / 902$
In previous studies, the predominance of this disease in female individuals and developing countries have been correlated to female hormones, cholesterol cycling and Salmonella-induced infections. 4,5 Moreover, bacterial cells serve as a base for formation of gall stones, while the resulting inflammations cause fibrosis and impair the gall bladder mobility. ${ }^{6}$

Chronic inflammations (developing due to any reason) that trigger the release of inflammation causing factors, active oxygen radicals, mutagenic toxins and metabolites, thereby impacting the regulation of cell cycle and underlying genetic predisposition to gall bladder cancer are two primary risk factors related to the incidence of gall bladder cancer.6,7

Porcelain gall bladder, Mirizzi's syndrome and bile reflux are few other factors increasing the predisposition of an individual to gall bladder cancer. ${ }^{4}$ Gall stones are also considered as a significant factor associated to gall bladder cancer.1,8 Incidences of gall bladder cancer has also been correlated to the socioeconomic conditions of patients and found to occur mostly in resource deficient countries. ${ }^{6}$

The most widely used tools for diagnosis of gall bladder cancer are Ultrasonography (USG), cholangiography, Computed Tomography (CT) and Magnetic Resonance Imaging (MRI). Diagnosis is also performed by histological analysis of gall bladder surgically removed for formation of benign gall stones. 
Often surgical removal alone does not ensure complete treatment and may have to be followed by chemoradiotherapy for ensuring long-term survival of patients. ${ }^{9,10}$ Evaluation of epidemiological data may suggest more significant yet treatable risk factors facilitating gall bladder cancer and help in establishing precise primary interventions. ${ }^{11}$ The present study was undertaken to analyse the different regional aetiological factors and investigate the clinical presentation and histopathology of gall bladder malignancy.

\section{MATERIALS AND METHODS}

This retrospective descriptive study was carried out in the Department of General Surgery, Himalayan Institute of Medical Sciences, Deharadun, Uttarakhand, India, with both prospective and retrospective data analysis. The retrospective study was carried out from May 2005 to April 2008 (3 years), while the prospective study was conducted from May 2007 to April 2008 (1 year).

Over the period of retrospective study, 110 patients clinically diagnosed with gall bladder carcinoma were identified. Their history and clinical findings (symptoms and signs) were recorded and assessed. Their clinical details, dietary habits, exposure to known carcinogens, physical symptoms and signs as well as socioeconomic status were also recorded in an investigator-designed proforma after obtaining an informed consent from the patient for identification of probable risk factors affecting the aetiopathogenesis of the disease. Patients of all age groups and belonging to male and female sexes were considered in this study.

\section{Inclusion and Exclusion Criteria}

All patients selected for this study had primary malignancy of gall bladder and extrahepatic biliary tract. Patients having secondary malignancy of gall bladder were however excluded from this study. Examinations for conclusive diagnosis and staging were also carried out and noted according to the proforma. Pathological staging of gall bladder carcinoma was performed according to the American Joint Commission on Cancer (AJCC). Description of the treatment was provided and its subsequent outcome were recorded during discharge and tracked for a maximum duration of 3 months.

\section{Study Details}

87 patients were identified for the prospective study, of which 8 left prior to completion of investigation. Thorough diagnosis of the remaining 79 patients was performed. In these patients, diagnosis of gall bladder carcinoma was validated by tools like USG-guided FNAC, laparotomy and laparoscopy for 72, 26 and 10 patients respectively.

\section{RESULTS}

\section{Age and Sex Distribution}

Age, sex and details of diagnosis of patients considered for the retrospective study has been given in Table 1. Symptoms and signs demonstrated by these patients have been given in Tables 2 and 3 and Figures 1 and 2 respectively. Of all patients considered in the retrospective study palliative biliary drainage was carried out in 2, while $35 \%$ patients were discharged on the basis of clinical suspicion only.
For the prospective study, patients considered were aged between 18 and 85 years, the average age being 44.4 years. Almost $80 \%$ of all patients were aged between 31 - 50 years, the youngest and the oldest being a female of 18 years and a male of 85 years respectively. $26.4 \%$ and $73.5 \%$ of all patients were males and females respectively with the Male: Female ratio being 23: 64 (1: 2.9).

\section{Dietary Habits}

The dietary details of these patients have been enlisted in Table 4. The four common and major aspects of dietary habit considered in this study included the nature of diet, cooking oil used, source of milk and source of water.

According to the results tabulated in Table 4, significant number of cases was non-vegetarian eaters. Results had also indicated that consumption of buffalo milk had caused a significant increase of risk (56.3\%). Usage of mustard oil (sold open) as cooking medium by majority of the patients was also found to pose a risk of $51.7 \%$. $57.5 \%$ of all gall bladder cancer patients were found to consume drinking water drawn from hand pumps.

\section{Demographic Profiles}

Correlation of demographic profiles of the patients considered for prospective studies and the manifestation of gall bladder carcinoma has been given in Table 5 and Figure 3.

Results obtained in this study indicated that consumption of brought open mustard oil and multiparity were significant features of gall bladder cancer patients. Clustering of various demographic features revealed that significantly high risk of gall bladder cancer patients who were females aged above 40 years, had family history of gall bladder disease, consumed non-vegetarian diet and brought open mustard oil and had low socioeconomic status were more predisposed to gall bladder carcinoma.

\section{Symptoms and Signs}

Clinical symptoms and signs demonstrated by patients considered in the prospective study has been shown in Tables 6 and 7 and Figures 4 and 5 respectively. Results indicated that abdominal pain in the right hypochondrium was the commonest symptom present. This pain was colicky and vague deep seated as well as continuous in nature in $40 \%$ and $60 \%$ of the patients respectively.

Other common features included anorexia, weight loss, jaundice and lump in abdomen. The symptoms were found to be similar in both jaundiced and non-jaundiced patients. However, no patient suffered from intra-peritoneal haemorrhage. Duration of lump and jaundice recorded in patients considered for this study has been shown in Figures 6 and 7 respectively. $80 \%$ of the patients were detected with a right upper abdominal lump that was firm-to-hard in consistency and moving sideways with respiration. Jaundice was recorded in less than half of the patients considered in this study, while hepatomegaly was found in $50 \%$ of all considered cases. The liver was found to be enlarged, but smooth in $45 \%$ of patients.

\section{Clinical Diagnosis}

USG of the abdomen performed in all these patients indicated cholelithiasis and mass in gall bladder of 70 and 8 patients respectively. CT scans performed on 52 patients was 
diagnostic of gall bladder carcinoma. However, laparoscopy was performed in 19 cases only. Findings of the laparoscopic examinations have been enlisted in Table 8 and Figure 8. Patients detected with benign gall bladder lump were advised for laparotomy.

14 out of 19 patients were diagnosed with gall bladder carcinoma. 11 out of 14 was detected with hepatic metastasis and nodular secondaries over the liver surface. Of the remaining 3, 2 were jaundiced. In totality $7 / 14$ had jaundice and was detected to have a mass at the porta hepatis. In one patient who was deeply jaundiced, the laparoscopic findings revealed an enlarged gall bladder with thick wall which was muddy white in colour with a mass at porta hepatis. In this case, laparoscopy was followed by laparotomy.

Further dissection revealed a ring-like growth at the neck of the gall bladder and the patient was subjected to cholecystectomy with T-tube drainage. Biopsy confirmed that this patient had papillary carcinoma of gall bladder. In all other cases, patients confirmed by laparotomy were further treated with cholecystectomy with or without choledochotomy.

\section{Biopsy}

Biopsy was performed under direct vision at laparoscopy in $13 / 19$ patients $(72 \%)$ for confirming the findings of laparoscopic examinations. Post biopsy, the sites were always electrocoagulated. Biopsy confirmed the diagnosis of gall bladder carcinoma in $12 / 13$ patients. Detailed results obtained from conducted biopsy have been given in Table 9. In one patient diagnosed with gall bladder carcinoma, biopsy was not performed laparoscopically due to the probable risk of perforation of gall bladder.

In this case, laparotomy findings advised palliative surgery and the diagnosis was confirmed histopathologically. Another patient diagnosed with carcinoma head of pancreas had refused to undergo surgery and further follow-up. The final results of laparoscopy performed on 19 patients have been shown in Table 8. Major conclusions of retrospective and prospective studies have been given in Figures 9 and 10 respectively.

\begin{tabular}{|c|c|}
\hline Parameters & Total No. of Patients \\
\hline Clinically diagnosed carcinoma of gall bladder & 110 \\
\hline Pathological diagnosis confirmed & $72(65 \%)$ \\
\hline Discharged on clinical diagnosis alone & $38(35 \%)$ \\
\hline Mean age (years) & $30-70$ \\
\hline Sex ratio (Female: Male) & $5: 1$ \\
\hline Table 1. Retrospective Study (May 2004 to April 2007) \\
\hline
\end{tabular}

\begin{tabular}{|c|c|c|}
\hline Symptoms & Present & Absent \\
\hline Upper abdominal pain & 81 & 29 \\
\hline Yellow discolouration of conjunctiva & 65 & 45 \\
\hline Weight loss & 76 & 34 \\
\hline Anorexia & 73 & 37 \\
\hline Pruritus & 15 & 95 \\
\hline \multicolumn{3}{|c|}{ Table 2. Symptoms of Gall Bladder Cancer in Subjects of Retrospective Study (n=110) } \\
\hline Signs & Present & Absent \\
\hline Jaundice & 51 & 59 \\
\hline Upper abdominal lump & 104 & 6 \\
\hline Hepatomegaly & 69 & 41 \\
\hline Splenomegaly & 2 & 108 \\
\hline Supraclavicular lymph node & 15 & 95 \\
\hline Ascites & 34 & 76 \\
\hline \multicolumn{3}{|c|}{ Table 3. Symptoms of Gall Bladder Cancer in subjects of Retrospective Study (n=110) } \\
\hline
\end{tabular}

\begin{tabular}{|c|c|c|c|}
\hline \multicolumn{2}{|c|}{ Diet } & Gall Bladder Cancer & Percentage \\
\hline Non-Vegetarian & & 58 & 66.7 \\
\hline \multirow{2}{*}{ Milk } & Cow & 38 & 43.7 \\
\cline { 2 - 4 } & Buffalo & 49 & 56.3 \\
\hline \multirow{2}{*}{$\begin{array}{c}\text { Mustard } \\
\text { oil }\end{array}$} & Home grown & 27 & 31 \\
\cline { 2 - 4 } & Sealed pack & 15 & 17.2 \\
\cline { 2 - 4 } Source of water & Brought open & 45 & 51.7 \\
\cline { 2 - 4 } & Well water & 8 & 9.2 \\
\cline { 2 - 4 } & Hand pump & 29 & 37.5 \\
\cline { 2 - 4 } & \multicolumn{2}{c|}{ Tap water } & 3.3 \\
\hline
\end{tabular}

\begin{tabular}{|c|c|c|}
\hline $\begin{array}{c}\text { Demographic Profile } \\
\text { of Low Socioeconomic } \\
\text { Status Group }\end{array}$ & $\begin{array}{c}\text { Number of Gall } \\
\text { Bladder Cancer } \\
\text { Patients (n= 87) }\end{array}$ & Percentage \\
\hline Rural residence & 67 & 77.0 \\
\hline
\end{tabular}




\begin{tabular}{|c|c|c|}
\hline Multiparous female & 45 & 51.7 \\
\hline Non-vegetarian & 58 & 66.7 \\
\hline Water source (Hand pump) & 50 & 57.5 \\
\hline Openly brought mustard oil & 45 & 51.7 \\
\hline \multicolumn{2}{|c|}{ Table 5. Correlation of Low Socioeconomic Status with Demographic Profile } \\
\hline
\end{tabular}

\begin{tabular}{|c|c|c|c|c|}
\hline Symptoms & Present & $\%$ & Absent & $\%$ \\
\hline Pain abdomen & 52 & 59.8 & 35 & 40.2 \\
\hline Upper abdominal lump & 70 & 80.5 & 17 & 19.5 \\
\hline Jaundice & 35 & 40.2 & 52 & 59.8 \\
\hline Weight loss & 40 & 46.0 & 47 & 54.0 \\
\hline Anorexia & 45 & 51.7 & 42 & 48.3 \\
\hline Pruritus & 15 & 17.2 & 72 & 82.8 \\
\hline Fever & 20 & 23.0 & 67 & 77.0 \\
\hline Clay coloured stool & 23 & 26.4 & 65 & -74.7 \\
\hline
\end{tabular}

\begin{tabular}{|c|c|c|c|c|}
\hline $\begin{array}{l}\text { Physical Signs } \\
\end{array}$ & Present & $\%$ & Absent & $\%$ \\
\hline Right hypochondrial tenderness & 30 & 34.5 & 57 & 65.5 \\
\hline Jaundice & 35 & 40.2 & 52 & 59.8 \\
\hline Right upper abdominal lump & 70 & 80.5 & 17 & 19.5 \\
\hline Liver (Hepatomegaly) & 44 & 50.6 & 43 & 49.4 \\
\hline Weight loss & 40 & 46.0 & 47 & 54.0 \\
\hline Lymph node & 5 & 5.7 & 82 & 94.3 \\
\hline Ascites & 17 & 19.5 & 70 & 80.5 \\
\hline Anaemia & 22 & 25.3 & 65 & 74.7 \\
\hline Gastric outlet obstruction & 7 & 8.0 & 80 & 92.0 \\
\hline Colonic obstruction & 2 & 2.3 & 85 & 97.7 \\
\hline \multicolumn{5}{|c|}{ Table 7. Signs of Gall Bladder Cancer in Subjects of Prospective Study (n=87) } \\
\hline \multicolumn{2}{|l|}{ Diagnosis } & \multicolumn{2}{|c|}{ No. of Cases } & $\%$ \\
\hline \multicolumn{2}{|l|}{ Benign gall bladder lump } & \multicolumn{2}{|c|}{3} & 15.8 \\
\hline \multicolumn{2}{|l|}{ Malignant gall bladder lump without metastasis } & \multicolumn{2}{|c|}{3} & 15.8 \\
\hline \multicolumn{2}{|l|}{ Liver secondary } & \multicolumn{2}{|c|}{11} & 57.9 \\
\hline \multicolumn{2}{|l|}{ Inconclusive } & \multicolumn{2}{|c|}{1} & 5.3 \\
\hline \multicolumn{2}{|l|}{ Carcinoma head of pancreas } & \multicolumn{2}{|c|}{1} & 5.3 \\
\hline Table 8. Laparoscopic Findings in & ts of Pr & & & \\
\hline
\end{tabular}

\begin{tabular}{|c|c|c|c|c|}
\hline Diagnosis & $\begin{array}{c}\text { No. } \\
\text { of Cases }\end{array}$ & $\begin{array}{c}\text { Biopsy } \\
\text { taken at } \\
\text { Laparoscopy }\end{array}$ & $\begin{array}{c}\text { Laparotomy } \\
\text { Advised }\end{array}$ & $\begin{array}{c}\text { Biopsy } \\
\text { after } \\
\text { Laparotomy }\end{array}$ \\
\hline $\begin{array}{c}\text { Carcinoma gallbladder with hepatic } \\
\text { metastases }\end{array}$ & 11 & 11 & 0 & 0 \\
\hline $\begin{array}{c}\text { Carcinoma gall bladder without hepatic } \\
\text { metastases }\end{array}$ & 3 & 2 & 13 & 13 \\
\hline Benign gall bladder lump & 3 & 0 & 3 & 3 \\
\hline Inclusive & 1 & 0 & 1 & 1 \\
\hline Carcinoma head of pancreas & 1 & $\mathbf{1 3}$ & $\mathbf{1 8}$ \\
\hline Total & $\mathbf{1 9}$ & Table 9. Details of Biopsy & \\
\hline \multicolumn{2}{|r|}{} \\
\hline
\end{tabular}




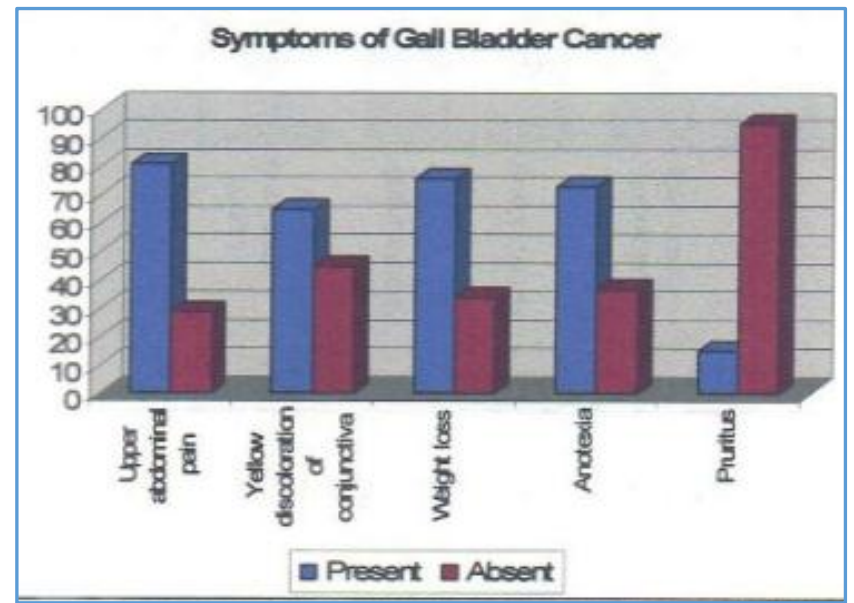

Figure 1. Symptoms of Gall Bladder Cancer in Subjects of Retrospective Study $(n=110)$

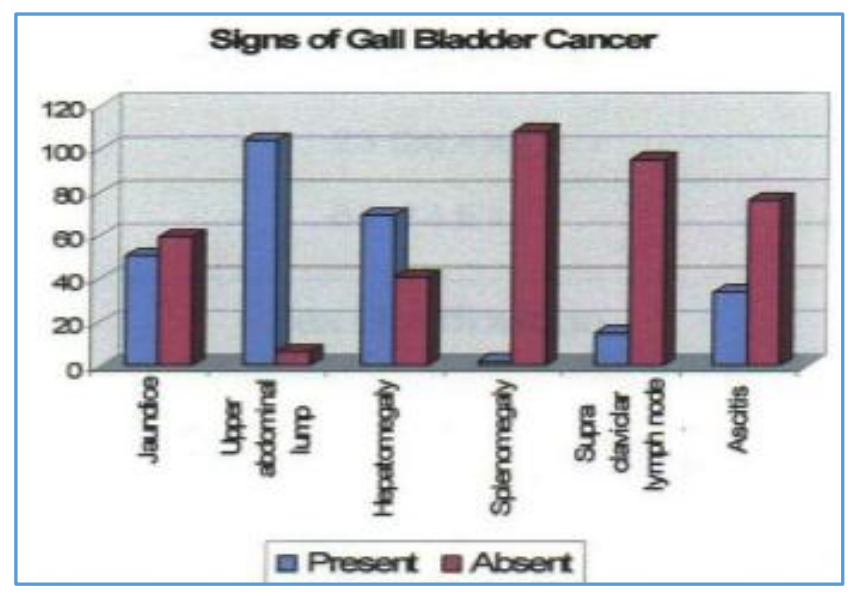

Figure 2. Signs of Gall Bladder Cancer in Subjects of Retrospective Study $(n=110)$

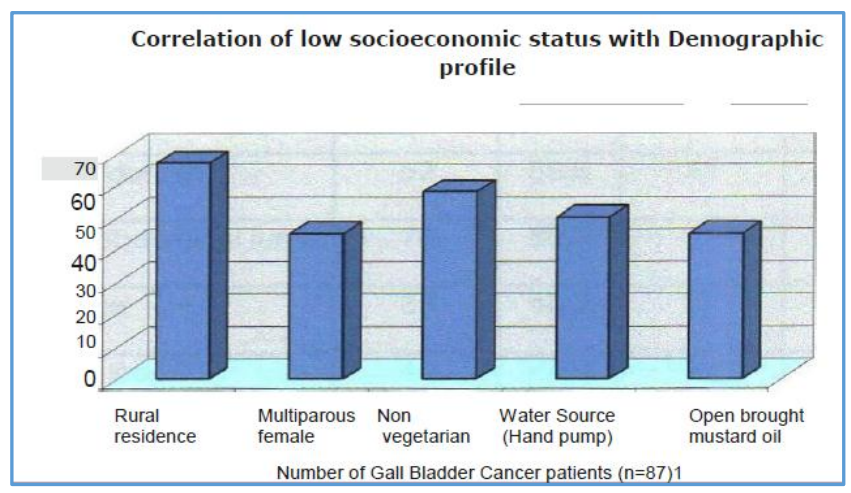

Figure 3

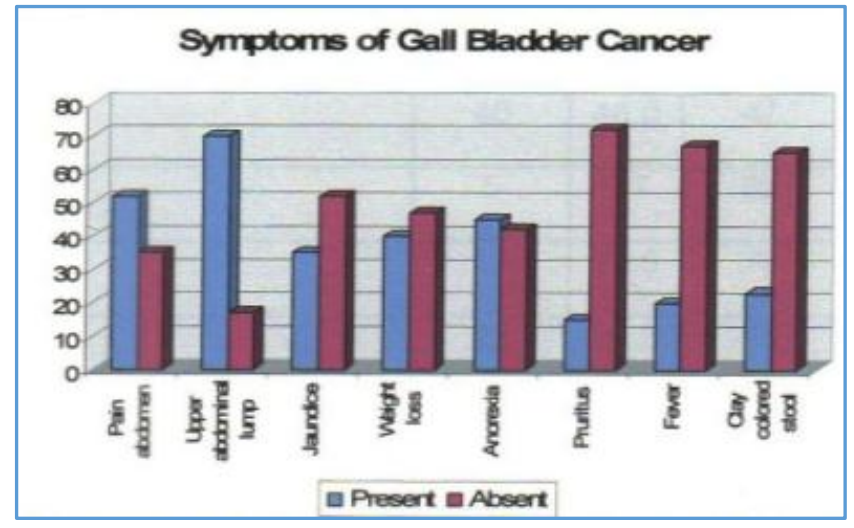

Figure 4. Symptoms of Gall Bladder Cancer in Subjects of Prospective Study $(n=87)$

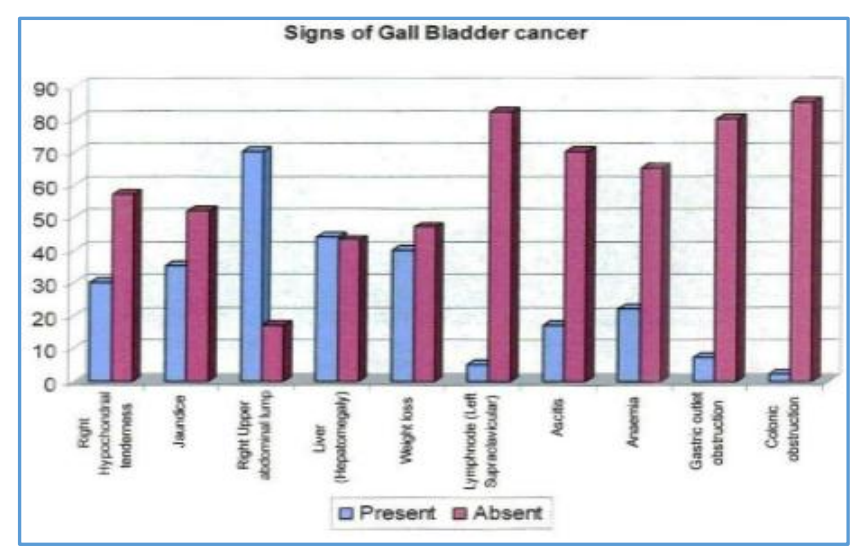

Figure 5. Signs of Gall Bladder Cancer in Subjects of Prospective Study $(n=87)$

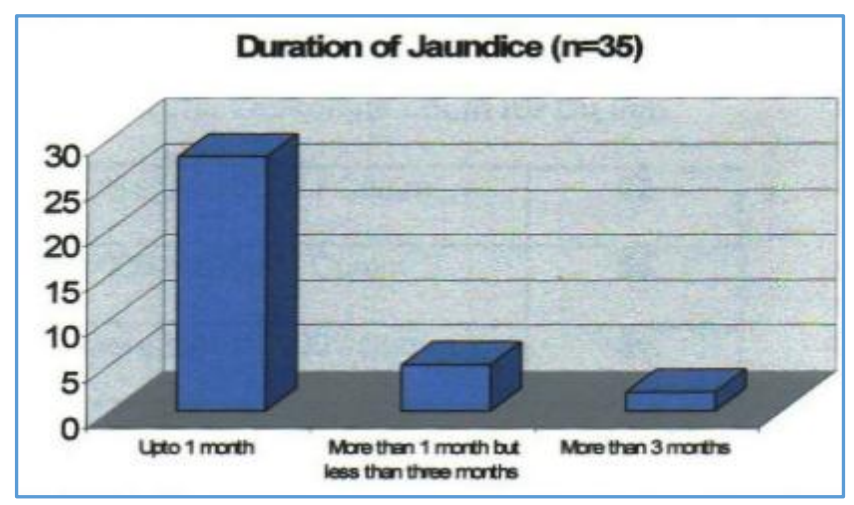

Figure 6. Duration of Jaundice in Subjects considered for Prospective Study

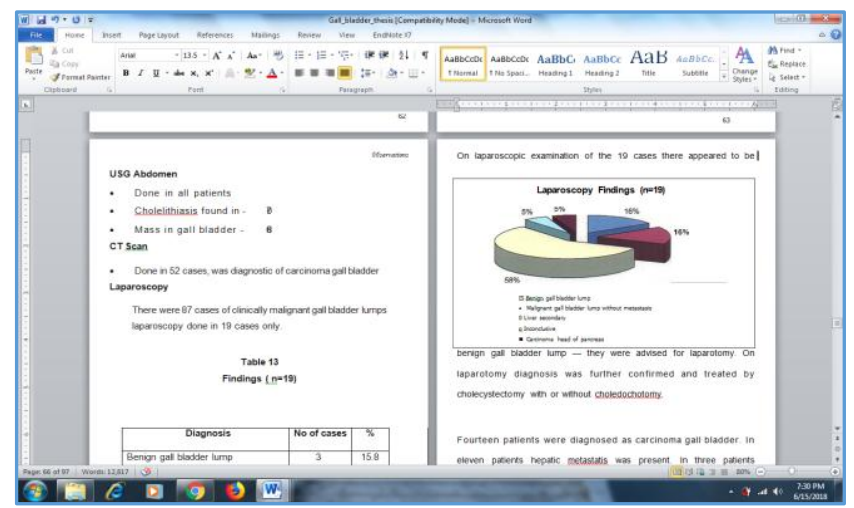

Figure 7. Laparoscopic Findings in Subjects of Prospective Study $(n=19)$ 


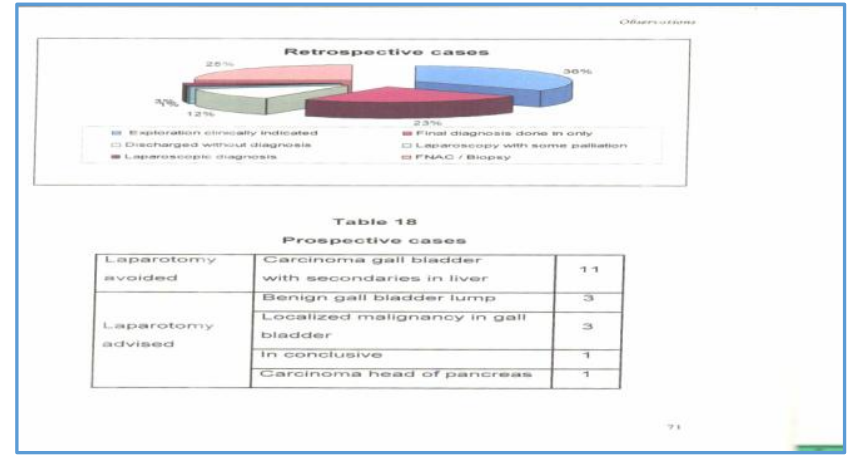

Figure 8. Details of Diagnosis in Retrospective Cases

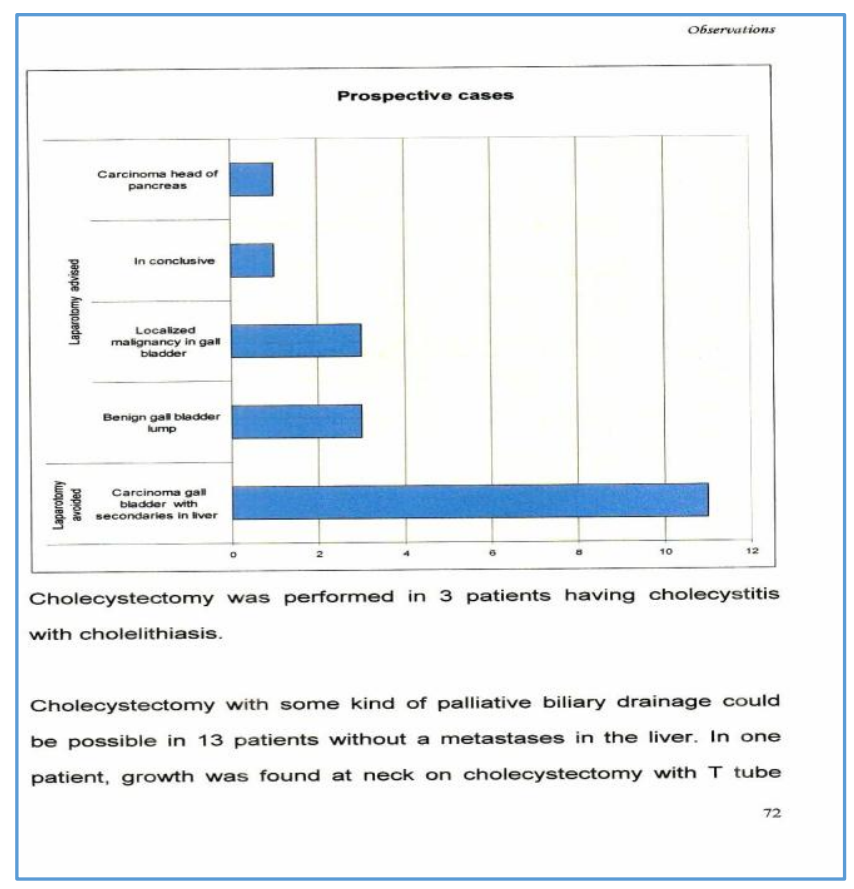

Figure 9. Details of Diagnosis in Prospective Cases

\section{DISCUSSION}

From the results obtained in this study, it could be concluded that the occurrence of gall bladder carcinoma was predominant in lower age groups than those reported in western literature with higher incidence in females. The higher predisposition to cancer may have had resulted from damages of gene and immune functions resulting from progress in lifespan. ${ }^{12}$ Similar results were also reported in previous studies. 13,14

It has also been reported that higher number of pregnancies and prolonged fertility enhance the risk of extrahepatic biliary tract malignancies. ${ }^{15,16}$ Incidences of gall bladder carcinoma were also found to be affected by dietary habits and socioeconomic status with most of the patients hailing from rural habitats as reported in previous investigations. ${ }^{17,18}$ Consumption of non-vegetarian diet and low dietary fibre reported in this study could contribute to aetiology of gall bladder cancer. In this study majority of cases consumed mustard oil, which too that was bought open, suggesting possible adulteration with some carcinogens.

The dismal prognosis of gall bladder carcinoma has been thought to be due to its symptomless primary stages. However, patients suffering from jaundice had reported earlier than patients with multiple hepatic metastases. $75 \%$ of patients undergoing palliative biliary drainage operation post cholecystectomy and $80 \%$ of gall bladder carcinoma patients subjected to USG were found to have gall stones.

Of the gall bladder removed for cancer, $80 \%$ was associated with gall stones. Similar studies have reported that majority of patients diagnosed with carcinoma were found to have gall stones, thereby establishing gall stones as a significant predisposing factor. ${ }^{19}$

Of the laparoscopic biopsy conducted in $25 \%$ of patients, only $0.13 \%$ was inclusive. While most of these patients were diagnosed with metastasising or infiltrating adenocarcinoma, two patients were diagnosed with papillary and adenosquamous carcinoma of the gall bladder respectively. Radical cancer operations have been associated with a $15 \%$ to $20 \%$ mean operative mortality.

In this study, most of the patients were in such stage that major operative curative procedure could not be performed on them. Even after palliative operation, the mortality was $25 \%$. Similar rates of mortality were reported by Hundal and Shaffer. ${ }^{20}$

In this study, the conclusive diagnosis was provided by laparoscopic examinations performed under local anaesthesia. Laparoscopic examinations were found to reduce morbidity (Induced by general anaesthesia), cost and duration of hospital stay associated with laparotomy. However, in comparison to laparoscopic examinations, sophisticated imaging tools like USG and CT scans were found to be more efficient for diagnosis of gall bladder carcinoma.

As this study had considered only those patients clinically diagnosed with gall bladder carcinoma, no patient of both prospective and retrospective investigation groups were found to have a localised disease. Hence, it may be concluded that confirmed detection of gall bladder carcinoma in its early stages still remain a challenge due to the unavailability of curative cholecystectomy and requires further investigations for appropriate clinical diagnosis of this disease.

\section{CONCLUSION}

Results obtained in this study indicate that aetiological factors causing gall bladder carcinoma are continuously changing for a population subgroup with corresponding alterations in lifestyle, exposure to toxins and dietary habits. In this study, conclusive diagnosis of gall bladder cancer was provided by laparoscopic examinations. However, further investigations are required to determine the preventable factors causing the widespread manifestations of this disease.

\section{REFERENCES}

[1] Sharma A, Sharma KL, Gupta A, et al. Gallbladder cancer epidemiology, pathogenesis and molecular genetics: recent update. World J Gastroenterol 2017;23(22):3978-98.

[2] Hundal R, Shaffer EA. Gallbladder cancer: epidemiology and outcome. Clin Epidemiol 2014;6:99109.

[3] Andia ME, Hsing AW, Andreotti G, et al. Geographic variation of gallbladder cancer mortality and risk factors in Chile: a population-based ecologic study. Int J Cancer 2008;123(6):1411-6. 
[4] Pilgrim CH, Groeschl RT, Christians KK, et al. Modern perspectives on factors predisposing to the development of gallbladder cancer. HPB (Oxford) 2013;15(11):839-44.

[5] Iyer P, Barreto SG, Sahoo B, et al. Non-typhoidal Salmonella DNA traces in gallbladder cancer. Infect Agent Cancer 2016;11:12.

[6] Bal MM, Ramadwar M, Deodhar K, et al. Pathology of gallbladder carcinoma: current understanding and new perspectives. Pathol Oncol Res 2015;21(3):50925.

[7] Nath G, Gulati AK, Shukla VK. Role of bacteria in carcinogenesis, with special reference to carcinoma of the gallbladder. World J Gastroenterol 2010;16(43):5395-404.

[8] Shrikhande SV, Barreto SG, Singh S, et al. Cholelithiasis in gallbladder cancer: coincidence, cofactor or cause! Eur J Surg Oncol 2010;36(6):514-9.

[9] Jayaraman S, Jarnagin WR. Management of gallbladder cancer. Gastroenterol Clinics North Am 2010;39(2):331-42.

[10] Shirai Y, Wakai T, Sakata J, et al. Regional lymphadenectomy for gallbladder cancer: rational extent, technical details and patient outcomes. World J Gastroenterol 2012;18(22):2775-83.

[11] Gupta S, Kori C, Kumar V, et al. Epidemiological study of gallbladder cancer patients from North Indian Gangetic Planes-a high-volume centre's experience. J Gastrointest Cancer 2016;47(1):27-35.

[12] Papaioannou S, Kotsampasopoulou I, Chaitidou S, et al. Gallbladder carcinoma imaging: Evaluation with U/S, CT, MRI. Hellenic J Radiol 2016;44(3):182-92.
[13] Le MD, Henson D, Young $H$, et al. Is gallbladder cancer decreasing in view of increasing laparoscopic cholecystectomy? Annals Hepatol 2011;10(3):306-14.

[14] Torre LA, Siegel RL, Islami F, et al. Worldwide burden of and trends in mortality from gallbladder and other biliary tract cancers. Clinical Gastroenterol Hepatol 2018;16(3):427-37.

[15] Makiuchi T, Sobue T, Kitamura T, et al. Reproductive factors and gallbladder/bile duct cancer: a populationbased cohort study in Japan. European J Cancer Prev 2017;26(4):292-300.

[16] Högnäs E, Kauppila A, Hinkula M, et al. Incidence of cancer among grand multiparous women in Finland with special focus on non-gynaecological cancers: a population-based cohort study. Acta Oncol 2016;55(3):370-6.

[17] Bosetti C, Turati F, La Vecchia C. Hepatocellular carcinoma epidemiology. Best Pract Res Clin Gastroenterol 2014;28(5):753-70.

[18] Makiuchi T, Sobue T, Kitamura T, et al. The relationship between vegetable/fruit consumption and gallbladder/bile duct cancer: a population-based cohort study in Japan. Int J Cancer 2017;140(5):100919.

[19] Dwivedi AN, Jain S, Dixit R. Gall bladder carcinoma: aggressive malignancy with protean loco-regional and distant spread. World J Clinical Cases 2015;3(3):23144. 